\title{
CRITICAL ASSESSMENT OF THE AMBIVALENT POTENTIALS OF SOCIAL MEDIA USE IN COVID 19 PANDEMIC CAMPAIGNS
}

\author{
Ephraim Ejimnkeonye Ezebuenyi, Ph.D \\ Department of Mass Communication \\ Nnamdi Azikiwe University \\ ezebuenyiee@gmail.com \\ 08037344823 \\ Rosemary Obianuju Ekwunife \\ Department Of Mass Communication, \\ Chukwuemeka Odumegwu Ojukwu University, \\ Igbariam Campus \\ rosyekwus@yahoo.com \\ 08063007409 \\ Felicia Chinyere Nweke \\ Department Of Mass Communication, \\ Chukwuemeka Odumegwu Ojukwu University, \\ Igbariam Campus \\ nwekefc@gmail.com \\ 08030450706
}

\begin{abstract}
The fear created by the Coronavirus as seen in the world today and the manner social media is churning out all manner of information (misinformation, disinformation, memes, innuendos, half - truths, lies etc.) about its cure and prevention is creating a situation of uncertainty. The situation becomes more disturbing since none of the claims in social media platforms regarding the therapies and recipes (solutions) for the cure or prevention of COVID-19 has been approved or certified by the World Health Organisation (WHO) or the Centre for Disease Control (CDC). It seems, however, that only the prevalence of social media can suffice for the provision of adequate, regular and up - to - date information on the pandemic. This can also explain the reason for leveraging social media platforms to enhance fast and wide diffusion of knowledge about Coronavirus all over the world. By its nature, social media allows for information to be readily shared - a role it has seemingly played in the face of the COVID. 19 pandemic - and unlike traditional news outlets there is no filter, no fact-checking and often a lot of bias. It becomes imperative therefore to assess the ambivalent potentials which social media display in the face of COVID. 19 pandemic vis-à-vis the impacts they have on the consumers of the information. The paper adopted the library research approach in which relevant conceptual literatures and empirical studies were analysed with the aim to ascertain whether social media display ambivalence in the campaign against the spread of COVID-19. The paper found, among others that the ambivalent potentials of social media use in the campaign against COVID-19 was glaring. It recommends, among others that consumers of social media products in this period should listen more to and, or check for updates by governments and other authorised agencies such as WHO and CDC rather than relying on unwholesome information from social media platforms.
\end{abstract}

Keywords: Critical assessment, Ambivalent potentials, Social media use, COVID-19 pandemic 
Volume 1 Number 1 Maiden Issue

\section{INTRODUCTION}

People did not have the same sources of communication we now have in the 21 st century to quickly share news and information during the 1918 flu pandemic, which the CDC estimates infected a third of the world's population. During that period, a public health report on Minneapolis's response to the 1918 flu shows that critical information regarding the virus were shared via postal workers, Boy Scouts, and teachers (Kushner, 2020). Today, however, in the face of COVID-19 pandemic social media platforms seem to provide that critical information without physical contacts.

The advent of Information and Communication Technology (ICT) - the harbinger of social media in the 21st century had enabled a new way of creating and disseminating information giving credence to the submission of Nwabueze and Ezebuenyi (2012); Ezebuenyi (2014); Igboeli, Ezebuenyi \& Onuigbo (2015); Ezebuenyi, Anagba \& Okika (2018), who held that technology has revolutionised almost all the activities of humans. Today, not only are we learning the latest news updates, but also, using platforms like Facebook, Twitter, Instagram etc. to provide personal and business updates. For businesses, this means leveraging social media to disseminate information on products and services as well as link sellers and buyers together, support employees and customers better than before. For the government, it means doing its best to share up-to-date information.

In this period of COVID-19 pandemic, social media have become a good means for individuals and communities to stay connected even while physically separated (Kushner, 2020). Also, the ambivalent potentials of social media observed in this period as witnessed by the manner of information (misinformation, memes, jokes, distractions etc.) circulated on social media platforms have created a situation fraught with uncertainty. The Coronavirus, which was declared a pandemic by the World Health Organisation (WHO) had affected the usage of social media by the world's general population among others; celebrities, world leaders, professionals (WHO, 2020). Social networking services have shared information, and created humour and distraction from the pandemic via Internet memes (Okwodu, 2020).These social network dynamics and their problematic role in spreading information of ambivalent potentials have partially made the campaign against COVID-19 pandemic a frivolity or hoax.

There has been a sharp increase in the use of social media during the pandemic, mainly due to social distancing measures encouraged by many governments. With the 'stay at home' order by various governments to their citizens, many people have turned to social media not only to access information on the pandemic but also, to maintain their relationships and to access entertainment to pass the time (Gowan, 2020). Moreover, social distancing has forced lifestyle changes for many people, which can put a strain on their psyche. Many online counselling services that use social media have surfaced and continue to rise in popularity, purportedly connecting health workers or COVID-19 solutions with those who need them (Gowan, 2020).

The function of social media in the context of leveraging their ubiquitous characteristics to mount an impulsion in the campaign against COVID-19 pandemic necessitated an unwholesome freaky assemblage of information about therapies and, or supposedly useful recipes to either cure Coronavirus or get immunity against its attack. This has become the practice with various social media platforms churning out information (ambiguous claims) about therapies or recipes purportedly having solutions to Coronavirus all over the world. 
Among the ambiguous claims are; "the hot garlic, ginger and turmeric therapy", "the scent leaf, lemon and gin therapy", "the blanket and warm water therapy", "staying under an intense hot sun therapy", "the Madagascar therapy", "the "pizza, 'utazi' and 'uda' therapy" etc., which different social media platforms post online as solutions to the Coronavirus.

The above posts are just a few out of the many claims being circulated in social media about the cure or solutions to the COVID-19 pandemic albeit unconfirmed/unapproved/uncertified by appropriate authorities. The fact that social media platforms, can in addition to disseminating breaking news and dishing out crucial information on world events, also circulate misinformation, memes, jokes, distractions and unwholesome information on critical situations such as COVID-19 pandemic is a proof of their ambivalent potentials. It also raises the source credibility question.

The problem therefore is that with the expected spread of this unwholesome information via social media platforms, people may be tempted to apply these recipes and end up harming their lives. Agreed that social media have enhanced to a great extent the diffusion of information on the propensity of COVID-19 pandemic containment, their use in spreading falsehood or misinformation that could be detrimental to human lives have also pervaded the society and has portrayed social media platforms as "a coin with two sides." The lives of the people should remain paramount in any circumstance. Pecuniary issues or puniness should not be allowed to interfere with any information relating to peoples' health and lives. Thus, this study seeks to establish the fact that social media platforms have displayed ambivalent potentials in their bid to proffer solutions to Coronavirus through library research approach and as well suggests best means possible to cushion its impact on the consumers of social media products in the face of COVID-19 pandemic.

\section{AN OVERVIEW OF THE ORIGIN OF CORONA VIRUS DISEASE (COVID-19)}

The Coronavirus (COVID-19) is a highly transmittable and pathogenic viral infection caused by Severe Acute Respiratory Syndrome Coronavirus 2 (SARS-CoV-2), which emerged in Wuhan, China and spread around the world. Genomic analysis revealed that SARS-CoV-2 is phylogenetically related to Severe Acute Respiratory Syndrome-like (SARS-like) bat viruses, therefore bats could be the possible primary reservoir (Shereen, Khan, Kazmi, Bashir\&Siddique, 2020). The common source of origin and transfer to humans is not known, however the rapid human to human transmission was confirmed widely. According to Shereen et al. (2020), there is no clinically approved antiviral medication or vaccine available to be used against COVID-19. However, a few broad-spectrum antiviral medications evaluated against COVID-19 in clinical trials, resulted in clinical recovery.

Approaching the end of 2019, Wuhan an emerging business hub of China experienced an outbreak of a novel Coronavirus that killed more than eighteen hundred and infected over seventy thousand individuals within the first fifty days of the epidemic. This virus was reported to be a member of the B group of Coronaviruses. According to Cui, Li \& Shi (2019) the novel virus was called COVID-19 by the Chinese researchers. The International Committee on Taxonomy of Viruses (ICTV) named the virus as SARS-CoV-2 and the disease as COVID-19 (Cui, Li \& Shi, 2019). In history, SRAS-CoV in 2003 infected 8,098 individuals with a mortality rate of $9 \%$, across 26 countries in the world.On the other hand, the novel Coronavirus in 2019 infected 120,000 individuals with a mortality rate of $2.9 \%$, across 109 countries. It shows that the transmission rate of SARS-CoV-2 is higher than $\mathrm{SRAS}-\mathrm{CoV}$ and the reason could be genetic recombination event at $\mathrm{S}$ protein in the RBD 
region of SARS-CoV-2 might have enhanced its transmission ability (Lai,Shih,Ko, Tang\&Hsueh,2019).

Towards the end of 2019, the World Health Organisation (WHO) was informed by the Chinese Government about several cases of pneumonia with unfamiliar aetiology. The outbreak was initiated from the human seafood market in Wuhan city of China and rapidly infected more than 50 peoples. The live animals such as bats, frogs, snakes, birds, marmots and rabbits were frequently sold at the human seafood market (Wang, Horby, Hayden \& Gao, 2020). On 12 January 2020, the National Health Commission of China released further details about the epidemic, suggested viral pneumonia (Wang, Horby, Hayden \& Gao, 2020). From the sequence-based analysis of isolates from the patients, the virus became known as a novel Coronavirus.

Moreover, the genetic sequence was provided for the diagnosis of viral infection. Initially, the patients infected with Wuhan Coronavirus induced pneumonia in China were said to have visited the seafood market where live animals were sold or may have used infected animals or birds as a source of food. However, further investigations revealed that some individuals contracted the infection even with no record of visiting the seafood market. These observations indicated a human-to-human spreading capability of this virus and then reported in more than 100 countries in the world. The human-to-human spreading of the virus occurs due to close contact with an infected person, exposed to coughing, sneezing, respiratory droplets or aerosols. These aerosols can penetrate the human body (lungs) via inhalation through the nose or mouth (Phan, Nguyen, Luong, Nguyen, Nguyen \& Le, 2020; Riou \& Althaus, 2020).

\section{CONCEPTUAL OVERVIEW OF SOCIAL MEDIA}

Many scholars, journalists and individuals have adopted different interpretations and concepts of what social media is. To define "social media" for our current purposes, we synthesize definitions presented in the literature and identify the following commonalities among current social media services:

*Social media services are (currently) Web 2.0 Internet-based applications,

*User-generated content is the lifeblood of social media,

*Individuals and groups create user-specific patterns for a site or app designed and maintained by a social media service,

*Social media services facilitate the development of social networks online by connecting a profile with those of other individuals and, or groups.

Social Media refers to online communication channels wherein users create and share content and interact with each other in many different ways (Boyd \& Ellison, 2007). These social media channels provide easily accessible and easily usable platforms and enable users to communicate with each other freely (Miller et al., 2016).With these, people can now share their opinions on everything to a large number of people much more quickly (Obar \& Wildman, 2015). It is common knowledge that social media is continuously updating itself. However, there are certain basic concepts which continue to be the same, and one should be aware of them to understand this world well.

\section{COVID 19 AND AMBIVALENT POTENTIALS OF SOCIAL MEDIA USES SPREADING INFORMATION}

Social media have been used by news outlets, organisations, and the general public to spread both valid information and misinformation about the pandemic (Llewellyn, 2020). The Centre 
for Disease Control (CDC), World Health Oorganisation (WHO), medical journals, and health care organisations have been updating and spreading knowledge across numerous platforms with partnerships with Facebook, Google Scholar and Twitter. Others such as an attending emergency medicine physician in the New York hospital system have been using their social media accounts to report firsthand accounts of working to combat COVID-19 (Kiefer, 2020). It was reported on 8 April, that COVID-19 conversations around disease states had increased $1,000 \%$ around healthcare professionals and 2,500\% among consumers based on a social listening study from $1^{\text {st }}$ January to $19^{\text {th }}$ March (Zarocostas, 2020)

According to Syner (2020), doctors are also joining groups on social media to spread knowledge about treating the disease with one group, the PMG COVID-19 Subgroup on Facebook reporting to some 30,000 members worldwide by the end of March. Another group, Physician Moms Group, which started five years before the pandemic had so many people wanting to join the 70,000 strong group on Facebook. The groups have allowed medical professionals to collaborate, gather information, and help direct supplies to hospitals that need them (Berg, 2020)

Smith, \& Fay Cortez, 2020) observed medical professionals have also used social media to educate the general population about the impact of working in PPE for upwards of twelvehour changes, utilising a trend that showcased their faces after their shifts, and their masks removed. Many of the individuals who participated had bruises, indents, redness and even band-aids covering blisters formed by the costumes sitting tight on their faces for hours.

\section{SPREADING MISINFORMATION}

A review from MIT Technology according to Law (2020) referred to Coronavirus pandemic as "the first true social-media 'infodemic"'. Also, a report from the National Geographic has stated that there is an increased level of "fake animal news" on social media during the pandemic (Hao, 2020).Past studies have shown how people have stopped getting their information from browsers, and other search methods in favour of relying on social media. Political bots are a popular way of spreading misinformation and propaganda, as well as manipulating the opinions of people. In the views of Donovan (2020), cases of propaganda and misinformation can vary by country. He further stated that misinformation could be dispersed strategically, but it can sometimes be spread by accident. Misinformation has the potential to make the pandemic more dangerous than it already is (Allen, Ryan, Gray, McInerney \& Waters, 2014; Berg, 2020).

Social media platforms have also contributed to the spread of misinformation. In Wuhan China panic has led to the spread of misinformation and even the disease itself. The report has it that misinformation has spread in the form of statements that fireworks will kill the virus in the air, as well as vinegar and indigo woad root curing the infection. According to Wernau (2020), this misinformation was spread through the messaging app WeChat.

In a sharp comparison, James R. Bailey, professor of leadership at the George Washington University School of Business posits: "It used to be that we consulted our local and national news sources, who had verifiable evidence for their reporting, but today, have an open platform that allows amateur journalists and opinionators to express themselves through halftruths, innuendo, rumour, and hearsay."

In a similar vein, the Reuters Institute for the Study of Journalism at the University of Oxford held "roughly one-third of social media users across the United States of America, as well a 
Argentina, Germany, South Korea, Spain and United Kingdom, published seeing false or misinformation about Coronavirus." The study held this is a problem with the media in general: "A majority of respondents in every country say that the news media have helped them understand the crisis and explain what they can do.

In words of Naim Kapucu, PhD., Pegasus Professor and Director, School of Public Administration at the University of Central Florida "The spread of misinformation is not new." According to Kapucu, "Misinformation, harmful content, and privacy issues have been major challenges for social media platforms." He went ahead to say that "Trusting content is especially critical as more people are using social media for news and updates." The digital platforms such as Facebook, YouTube, Reddit, and Twitter need serious considerations to address misinformation about COVID-19.

\section{THEORETICAL FRAMEWORK}

The concept 'technological determinism theory' also known as the medium theory explains the setting of this study. The theory which was propounded by Marshall McLuhan, a Canadian communication scholar in 1962, observes new media technologies in communication would soon determine social changes, turning the world into a global village. He believes socio-political, economic and cultural changes are inevitably based on development and diffusion of technology. McLuhan argued technology undoubtedly causes specific changes on how people think, how society is structured and the form of culture created. This theory portends that given the emergence of Internet and its adoption and relevance in mobilizing people for socio-cultural, economic and political activities, there's bound to be an impact on the way people behave, interact and communicate. The basic assumption of the theory also states that technology shapes how individual communicate, relate and interact in the society. It assumes media technology play a dominant role in the assignment of meaning in the society as well as shapes how we as individuals in a society think, feel, act, and how society operates as we move from one technological age to another.

According to McLuhan "...communication technology plays such a critical role in the emergence of new social orders and new forms of culture". Explaining the centrality of the theory to this study, Baran and Davis (2012, p.274) in their discourse of the medium theory said that McLuhan proclaimed that the medium is the message. In other words, new forms of media transform our experience of ourselves and our society, and this influence is ultimately more important than the content that is transmitted. In its specific messages, technology determines experience. Baran and Davis (2012) asked pertinent questions, which is believed to resonate with the core of the discourse in this paper. They queried: What has been your experience with the Internet in general, and social networking websites like Facebook and Twitter in particular? Have these sites changed the social world for better or worse?

The preceding questions make the basic assumption of the theory and its adoption as anchorage in this study relevant and applicable to the impact of social media on their users, vis-à-vis the ambivalent potentials displayed in the face of COVID-19 pandemic campaign. These technological innovations have changed the landscape of not only the creation of messages but also the way such messages are transmitted quickly all over the world without recourse to fact-checking and source credibility. 


\section{DISCUSSION}

To determine whether the ambivalent nature of social media thrived in the face of COVID-19 pandemic, there is need to look at how individuals, businesses, and government agencies have passed messages and interacted with others on social media during the period under study. The aim is to throw up primary roles that social media platforms have played during the Coronavirus outbreak:

Firstly, as a source of information (and misinformation), there has not been more real-time data available at our fingertips in the face of a worldwide event. Such data can help keep us safe, providing us with a better understanding of what is happening and how it might impact our loved ones and us. Besides, social media can also spread falsehoods, including miracle preventative measures, false claims about therapies and recipes etc. This submission supports an earlier observation by Okwodu (2020), who stated that social networking services have shared information, and created humour and distraction from the pandemic via Internet memes. These social network dynamics and their problematic role in spreading information of ambivalent potentials have partially made the campaign against COVID-19 pandemic a frivolity or hoax.

At a time when many people are grappling with as much information as they can get their hands on, the public is especially susceptible to false and sometimes hazardous claims, which are passed on to others. Supporting the above observation, the Reuters Institute for the Study of Journalism at the University of Oxford stated "roughly one-third of social media users across the United States of America, as well as Argentina, Germany, South Korea, Spain and United Kingdom, published seeing false or misinformation about Coronavirus." The study held this is a problem with the media in general: "A majority of respondents in every country say that the news media have helped them understand the crisis and explain what they can do. However, about one in three also say they feel the news media have exaggerated the pandemic." Those exaggerations are amplified on social media.

Similarly, while Facebook, Google, LinkedIn, Microsoft, Reddit, Twitter and YouTube issued a joint statement and pledged to work together to combat misinformation it continues to spread as fast as the actual Coronavirus. Even before the pandemic, the social media platforms had been under pressure to address the spread of false news and misinformation, still now the situation seems to be getting worse, not better. The very nature of social media allows for information to be readily shared - and unlike traditional news outlets, there is no filter, no fact - checking and often a lot of bias. Reinforcing the above, James R. Bailey, professor of leadership at the George Washington University School of Business posits: It used to be that we consulted our local and national news sources, who had verifiable evidence for their reporting, but today, have an open platform that allows amateur journalists and opinionators to express themselves through half-truths, innuendo, rumour, and hearsay.

The above observation can be a reason to infer that social media platforms provide access, and opportunity to spread misinformation and rumours quickly.

In the words of Naim Kapucu, PhD., Pegasus Professor and Director, School of Public Administration at the University of Central Florida "The spread of misinformation is not new." According to Kapucu, "Misinformation, harmful content, and privacy issues have been major challenges for social media platforms." He went ahead to say that "Trusting content is especially critical as more people are using social media for news and updates." The digital 
platforms such as Facebook, YouTube, Reddit, and Twitter need serious considerations to address misinformation about COVID-19.

The best rule for making sure information is accurate is to check sources and make sure that those sources are indeed trustworthy, and the information was relayed accurately. Just because someone claims to have learned something from a reliable source does not mean he is sending that information correctly.

Secondly, influence on public response to the outbreak shows that billions of people are free to publicly share their opinions on COVID-19 across various social media platforms. Within this pandemic period, individuals, organizations, and businesses have been using social media to spread awareness of COVID-19, in addition to the public actions that were taken. The most distinct ways social media have influenced the public since the virus reached epidemic and pandemic levels includes trending information on social distancing and home quarantine.

It was just in the event of the emergence of COVID-19 pandemic that many of us started hearing of "social distancing," which refers to staying at least 6 feet away from others to help prevent the spread of infection. Now, social media users, from friends and family to celebrities and governments, are regularly calling for social distancing.Stay at home as much as possible. Listen to the experts, ignore the morons. The ambivalent potentials of social media has become so commonplace that there is always a forewarning in various social media platforms urging users to sieve the information they receive to stem the tendencies of acting on an unwholesome idea in the face of the COVID-19 pandemic.

\section{CONCLUSION/RECOMMENDATIONS}

No platform is perfect. But where there has been misinformation and fear on social media, there has also been an abundance of vital, lifesaving information, connection with others, and global unity. As with other misinformation that is spread on social media, there is often no filter to determine if the information is accurate. In the face of COVID-19 pandemic, people have shown their support and empathy on social media. It is human nature to search for guidance, information and direction during times of crisis. However, during those times, and this pandemic, it is vitally important to consider the validity of a source and seek out the advice of experts. Explore the correctness of the information and look for the 'experts in the field' such as, the Center for Disease Control (CDC) or the State Health Department.

The critical task at hand should be providing accurate information regularly at every platform, including social media, as frequently as possible otherwise, the effort in sharing information will be spent on stopping or controlling the misinformation. When the misinformation is out on social media, stopping it is not easy. It is very critical during emergencies and crises that the public hears from leaders at every level of government the same, consistent message regularly. Free speech, libertarian, and corporate lobbyists continue to press for those who see benefits from misinformation online, making legislative changes to prevent the flow of misinformation online challenging to achieve.

Social media can be an excellent vehicle to reach the masses through the sharing of information. With so many who "benefit" from the creation and dissemination of misinformation, it's no wonder that it's hard to stop the flow. Mark Twain and Winston Churchill, both epigrammatic geniuses, observed that "lies travel halfway across the world before the truth has its shoes on," In fact, lies and truth are hard to distinguish these days 
COVID-19 pandemic. The above statement is true because despite numerous pieces of misinformation, falsehood unapproved/uncertified recipes that various social media platforms throw at users in the face of COVID-19 pandemic, there seems to be high acceptance level of these information on social media. The above submission can be attributed to the ambivalent potentials of social media uses in the face of COVID-19 pandemic, which also underscores the use of technological determinism theory in anchoring this study. The basic assumption of the theory is that technology shapes how individuals communicate, relate and interact in the society. In relation to the present study, the ambivalence displayed by social media platforms in creating and transmitting information on the prevalence and containment of the cascading Coronavirus in the world today reinforces the relevance of the technological determinism theory.

It is therefore the position of this paper that consumers of social media products during COVID-19 pandemic should listen more to and, or check for updates by country and other authorised agencies such as WHO and CDC rather than relying on unwholesome information from social media platforms. Finding trusted sources of information regarding COVID-19 is significant. Social media companies must find a way to combat misinformation on Coronavirus.

\section{REFERENCES}

A B C D COVID-19 (28 March, 2020). "Social media use goes up as country stays indoors", Victoria News, Melbourne. Retrieved 15 April, 2020

Allen, K. A., Ryan, T., Gray, D.L., McInerney, D. M., Waters, L. (July 2014). "Social media use and social connectedness in adolescents: The positives and the potential pitfalls". The Australian Educational and Developmental Psychologist. 31 (1), 18-31.

Baran, S.J. \& Davis, D.K. (2012) Mass communication theory: Foundation ferment and future. $\left(6^{\text {th }}\right.$ ed.). Boston MA: Wadsworth

Berg, S. (28 February, 2020). "Doctor uses the reach of social media to ease COVID-19 pandemic fears". American Medical Association.Retrieved 21 April 2020.

Boyd, D. M., \& Ellison, N. B. (2007). Social network sites: Definition, history, and scholarship. Journal of Computer-Mediated Communication, 13(1), 210-230.

Cui, J., Li, F., Shi, Z. (2019).Origin and evolution of pathogenic coronaviruses. Nat Rev Microbiol 2019;17(3):181-92.

Donovan, J. (2020). "Here how social media can combat the coronavirus'infodemic'". MIT Technology Review.

Ezebuenyi, E.E. (2014). The use of Facebook in enhancing electoral participation in Nigeria's 2011 presidential election. Unpublished M.Sc Dissertation submitted to the School of Postgraduate Studies, Anambra State University, Igbariam Campus.

Ezebuenyi, E.E., Anagba, E. and Okika, E. (2018). Social media use and social isolation among the youths: Implication on sustenance of human dignity in the $21^{\text {st }}$ century. ANSU Journal of Arts and Humanities (AJAH)Vol. 5 No 2, pp. 28-38 
Gowan, Rob (9 April, 2020). "WES for Youth Online sees surge in counselling service use". Owen Sound Sun-Times. Retrieved 15 April 2020.

Hao, K. (2020)."The coronavirus is the first true social-media 'infodemic'". MIT Technology Review

Kiefer, H. (18 April 2020). "Not only should you stream the phantom of the opera this weekend, you have to". Vulture. Retrieved 9 May 2020

Kushner, J. (2020). The role of social media in spreading COVID 19 information. https://doi.org/10.1177/2056305118764438

Lai, C., Shih, T., Ko, W., Tang, H., Hsueh, P. (2019). Severe acute respiratory syndrome coronavirus 2 (SARS-CoV-2) and coronavirus -2019 (COVID-19)

Law, T. (22 March, 2020). "Healthcare workers share selfies of exhausted faces after hard days treating COVID-19 patients". Times. Retrieved 21 April 2020.

Llewellyn, S. (25 March, 2020). "Covid-19: how to be careful with trust and expertise on social media". BMJ. 368: m1160. Doi:10.1136/bmj.m1160. PMID 32213480-via www.bmj.com.

Miller, D., et al. (2016). How the world changed social media. London: UCL Press.

Nicholson, T. (19 March, 2020). "These coronavirus memes will make life feel a little bit better". $\quad$ Esquire. Archived from the original on 27 March 2020.Retrieved 22 March 2020.

Nwabueze, C. D. and Ezebuenyi, E. E. (2012).Appraising the relevance of ICTs in awareness creation during elections. Journal of Linguistics and Communication Studies, 2, (1), 293- 302.

Obar, J.A. and Wildman, S. (2015). Social media definition and the governance challenge: An introduction to the special issue. Telecommunications Policy, 39(9), 745-750.; Quello Center Working Paper No. 2647377.

Okwodu, J. (2020)."We need joy to survive": Naomi Shimada on how to mindfully use social media in the age of social distancing". Vogue. Archived from the original on 26 March 2020.Retrieved 26 March 2020.

Phan, L.T., Nguyen, T.V., Luong, Q.C., Nguyen, T.V., Nguyen, H.T, Le, H.Q. (2020). Importation and human-to-human transmission of a novel coronavirus inVietnam. $N$ Engl J Med 2020.

Riou, J., Althaus, C.L. (2020).Pattern of early human-to-human transmission of Wuhan2019 novel coronavirus (2019-nCoV), December 2019 to January 2020.Eurosurveillance. 2020;25(4). 
Shereen, M.A., Khan, S., Kazmi, A., Bashir, N \& Siddique, R. (2020). COVID-19 infection: Origin, transmission, and characteristics of human coronaviruses. China: Wuhan University Press

Smith, M; Fay Cortez, M. (24 March, 2020). "Doctors turn to social media to develop COVID- $\quad 19$ treatments in real time". Bloomberg.Retrieved 21 April 2020.

Wang, C., Horby, P.W., Hayden, F.G., Gao, G.F. (2020).A novel coronavirus outbreak of global health concern. The Lancet 2020.

Wernau, J. (22 January, 2020). "Virus sparks Chinese panic buying, travel cancellations and social-media misinformation" - via www.wsj.com.

WHO (2020). Laboratory testing for coronavirus disease 2019 (COVID-19)in suspected human cases: interim guidance, 2 March 2020. World HealthOrganization, 2020.

Zarocostas, J. (29 February, 2020). "How to fight an infodemic".The Lancet. 395 (10225), 676. 